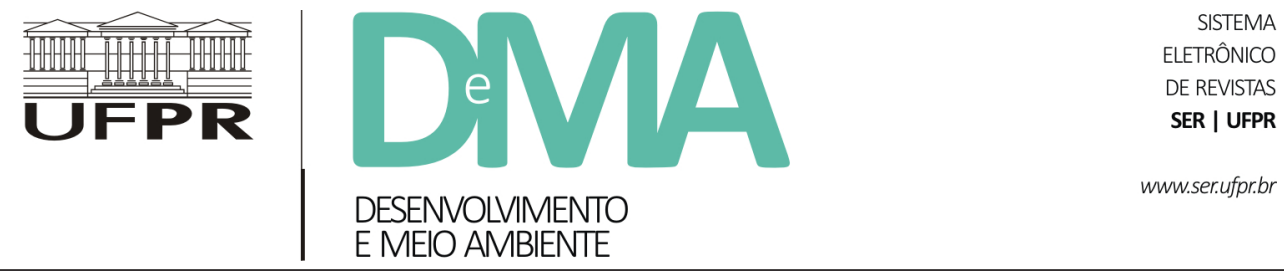

\title{
Indicadores de Bem Viver: pela valorização de identidades culturais
}

\section{Good Living indicators: for the valuation of cultural identities}

\author{
Liliane Cristine Schlemer ALCÂNTARA ${ }^{1,2 *}$, Carlos Alberto Cioce SAMPAIO ${ }^{3,4}$. \\ ${ }^{1}$ Universidade Federal do Mato Grosso (UFMT), Cuiabá, MT, Brasil. \\ ${ }^{2}$ Programa de Pós-graduação em Ciências Ambientais (PPGCA), Universidade do Estado de Mato Grosso (UNEMAT), Cáceres, Mato Grosso, \\ Brasil. \\ ${ }^{3}$ Universidade Regional de Blumenau (FURB), Blumenau, SC, Brasil. \\ ${ }^{4}$ Universidade Positivo (UP), Curitiba, PR, Brasil. \\ *E-mail de contato: lilianecsa@yahoo.com.br
}

Artigo recebido em 22 de novembro de 2018, versão final aceita em 8 de março de 2020, publicado em 18 de abril de 2020.

RESUMO: Atualmente, nos mais distintos contextos socioeconômico e ambiental, são privilegiados os indicadores de bemestar e de qualidade de vida, baseados em informações qualitativas e quantitativas sob a dimensão espaço-tempo. O objetivo deste artigo é apresentar uma proposta, no âmbito teórico-metodológico, de um sistema de indicadores de Bem Viver relacionado ao bem-estar subjetivo, superando os limites da mera quantificação econômica. A metodologia é bibliográfica com descrição narrativa. Sob os pontos de vista teórico e contextual, consiste de análise de referências da literatura, com interpretação e análise crítica. Apesar de o conceito estar em processo de construção, requerendo avanço no que se refere à conceptualização e operacionalização, propõe-se uma matriz de indicadores que sugerem utilidade para a medição das dimensões do Bem Viver, e que buscam uma complementaridade entre aspectos subjetivos, objetivos e intersubjetividade.

Palavras-chave: indicadores; bem viver; bem-estar; qualidade de vida; intersubjetividade.

ABSTRACT: Currently, in the most different socioeconomic and environmental contexts, the indicators of well-being and quality of life are privileged, based on qualitative and quantitative information in the space-time scope. The objective of this article is to present a proposal, in the theoretical-methodological framework, of a system of indicators of Good Living related to subjective well-being, overcoming the limits of mere economic quantification. The methodology is bibliographical with a narrative description. From both theoretical and contextual points of view, it consists of an analysis of literature references, with interpretation and critical 
analysis. Although the concept is in the process of construction, requiring progress in terms of conceptualization and operationalization, a matrix of indicators is proposed that suggest utility for measuring the dimensions of Good Living, which seek a complementarity between subjective and objective aspects and intersubjectivity.

Keywords: indicators; good living; welfare; quality of life; intersubjectivity.

\section{Introdução}

Foi recorrente considerar desenvolvimento sinônimo de crescimento econômico Nesse contexto, os indicadores de desenvolvimento se configuravam de maneira que as políticas sociais estivessem associadas, direta ou indiretamente, ao comportamento do Produto Interno Bruto (PIB). Segundo essa visão econômica reducionista, os países chamados mais desenvolvidos eram aqueles com maior PIB per capita. Esta corrente entendia que a produção econômica gerava riquezas, as quais, por consequência, produziam maior bem-estar econômico. A qualificação reducionista é também restritiva, no sentido a que se refere Amartya Sen quando faz menção a "visões mais restritas de desenvolvimento, como as que identificam desenvolvimento com crescimento do Produto Nacional Bruto (PNB), aumento de rendas pessoais, industrialização, avanço tecnológico ou modernização social" (Sen, 2000, p. 17).

Entretanto, "um PIB alto [...] não é garantia para a participação, a democracia, a liberdade, a equidade; tampouco o é para evitar problemas de drogas, alcoolismo, HIV/AIDS, habitação, ruptura familiar, corrupção, entre outros males sociais" (Phélan, 2011, p. 73, tradução nossa). O PIB não classifica corretamente o bem-estar das pessoas, pois é um indicador fundamentalmente econômico e unidimensional; indicadores sociais, na maneira como o adjetivo é normalmente usado, estão nele ausentes.

Reduzir as emissões de carbono, preservar a biodiversidade, promover o uso racional dos recursos e atingir nível de coesão social são desafios quando conciliados com a dimensão econômica do desenvolvimento. Nesta conjuntura, há que se superar "as visões clássicas do desenvolvimento como crescimento econômico perpétuo, o progresso linear e o antropocentrismo" (Gudynas, 2011, p. 50, tradução nossa) desmedido que se utiliza das conveniências do termo sustentabilidade.

Durante os últimos anos surgiram propostas alternativas à visão reducionista de crescimento econômico, baseadas em indicadores de bem-estar social e de qualidade de vida. Diante da diversidade de abordagens, "há um consenso generalizado sobre o caráter multidimensional destes conceitos, a estreita conexão existente entre eles, e as dificuldades inerentes a sua quantificação" (López-Menéndez, 2015, p. 199, tradução nossa). Neste contexto, tem-se como objetivo apresentar uma proposta, no âmbito teórico-metodológico, de um sistema de indicadores de Bem Viver relacionado ao bem-estar subjetivo, superando os limites da mera quantificação econômica.

Parte-se do pressuposto de que a discussão sobre o Bem Viver está enraizada na tradição de populações originárias latino-americanas como a da corrente indigenista e pachamamista, "caracterizada pela relevância que dão à autodeterminação 
dos povos indígenas assim como aos elementos mágico-espirituais [sic]" (Hidalgo-Capitán, 2012b, p. 48 , tradução nossa) $)^{1}$.

Este trabalho divide-se em cinco partes adicionais a esta introdução, que contemplam: a metodologia utilizada na construção de indicadores; uma seção sobre qualidade de vida, bem-estar e bem viver; e uma sobre indicadores subjetivos. Em seguida, apresentam-se resultados e discussões, que contemplam construção de indicadores do Bem Viver. Finaliza-se com a apresentação de uma matriz de indicadores que os autores julgam apropriada, a partir desta análise, como proposta de medição.

\section{Metodologia: desafios na construção de indicadores}

Indicadores de desenvolvimento são instrumentos analíticos elaborados com a intenção geral de melhorar as condições da vida social, o que remete à promoção do bem-estar de uma sociedade. Neste contexto, pode-se relacionar o conceito de bem-estar a aspectos como qualidade de vida, nível de renda, felicidade, Bem Viver, entre outros.

Com referência a bem-estar, componentes subjetivos referem-se, e dizem respeito, a opiniões, avaliações, sentimentos, percepções, atitudes, desejos, valores e motivações relacionados a cada vida individual como um todo ou em diferentes contextos específicos. Ao contrário de características objetivas, nenhum padrão explícito é definido e nenhuma referência externa pode ser definida em observando o componente subjetivo (Maggino, 2009, p. 6, tradução nossa).
Entretanto, a necessidade de dispor de um instrumento, que apesar das limitações, sugira uma conotação geral de bem-estar, tem levado à busca de indicadores globais que contenham esta dimensão, permitindo comparações (inter)territoriais e sua evolução temporal. A integração de modelos de explicitação da qualidade de vida é que permite falar do processo contínuo de percepção da vida:

[...] se dirigem a entender o bem-estar da população e sua integração permite falar do processo contínuo de percepção da vida, considerando a influência de dimensões objetivas e subjetivas que têm ingerência na percepção que os sujeitos vão tendo a respeito de sua própria vida (Rojas, 2005, p. 98, tradução nossa).

Um indicador, bem como sua régua de medição, deve conduzir a um estado de mudança e ser susceptível de revisão à medida que surjam disponíveis informações sistematizadas e novas metodologias: "Em muitos casos, o nível de indicadores sociais serve para ressaltar a importância do problema, mas em termos de política, como eles mudam ao longo do tempo é o que é crucial." (Marlier \& Atkinson, 2010, p. 288, tradução nossa).

Portanto, a construção de novas medidas de Bem Viver deve ser considerada como um processo dinâmico e de mudança, que pode melhorar no tempo conforme se compreenda melhor a conceptualização do Bem Viver e conforme se disponha de melhor informação (León, 2015, p. 14-15, tradução nossa).

\footnotetext{
${ }^{1}$ Além desta, há, também as vertentes socialista e estadista, "caracterizada pela relevância que dão à gestão político-estatal [sic] do Bem Viver, assim como aos elementos relativos à equidade social"; e pós-desenvolvimentista e ecologista, "caracterizada por relevância que dão à construção participativa do Bem Viver, com a inclusão de contribuições indigenistas, socialistas, feministas, teológicos e sobretudo ecologistas"; há, também, os críticos do Bem Viver, cujos intelectuais "tratam de negar sua validade intelectual e política" (Hidalgo-Capitán, $2012 b$, p. 49 e 51, tradução nossa).
} 
Apesar dos pontos positivos destes indicadores, as metodologias de bem-estar subjetivo referente à felicidade não estão isentas de questionamentos e críticas, como aponta a Oxford Poverty and Human Development Initiative (2011, p. 4, tradução nossa), que expressa que "a felicidade é extremamente 'sensível às circunstâncias de curto prazo'. [...] é uma emoção passageira, transitória [...]". O principal problema que os autores deste artigo identificam é a heterogeneidade das unidades de medida dos distintos indicadores e a existência de interdependência entre eles. Os desafios a que se deve fazer frente para a definição de indicadores de Bem Viver são complexos, ainda que se tenha em conta que os esforços realizados para conceber indicadores permitem dispor de marcos metodológicos que contribuem para seu significado.

No intuito de apresentar uma proposta de um sistema de indicadores de Bem Viver, superando os limites da mera quantificação econômica, utilizou-se na metodologia pesquisa bibliográfica não sistemática com descrição narrativa. Sob os pontos de vista teórico e contextual, constituiu-se de análise da literatura, com interpretação e análise crítica. Levantaram-se significativos indicadores de desenvolvimento mundiais existentes, inclusive iniciativas latino-americanas, cujas experiências tiveram protagonismo ao incorporar o Bem Viver em suas constituições, como os casos da República do Equador (Constitución de 2008 e Plan Nacional para el Buen Vivir 2013-2017) e do Estado Pluri- nacional da Bolívia (Nueva Constitución Política del Estado). Ressalta-se que o Equador está em sua terceira fase de metas para o desenvolvimento dentro do contexto do Bem Viver, correspondente ao Plan Nacional de Desarrollo 2017-2021: Toda una vida (Ecuador, 2017).

O estudo resultou em uma matriz de indicadores $^{2}$ para a medição de dimensões do Bem Viver que podem ser utilizadas na análise de modalidades de experiências ecológicas e socioeconômicas, e que são importantes para um processo participativo de planejamento de políticas públicas de sustentabilidade socioeconômica e ambiental.

\section{Qualidade de vida, bem-estar ou bem viver?}

A comissão que elaborou o relatório Nosso Futuro Comum pronunciou-se sobre a ideia de desenvolvimento sustentável: “[...] é o desenvolvimento que atende as necessidades do presente sem comprometer a capacidade de as gerações futuras atenderem suas próprias necessidades" (World Commission on Environment and Development, 1987, p. 41, tradução nossa). Os limites do desenvolvimento estão condicionados por estágio da tecnologia, organização da sociedade, intervenção sobre o ambiente e capacidade da biosfera absorver impactos das atividades do homem. Neste contexto, conceitos como o bem-estar relacionados com qua-

\footnotetext{
${ }^{2}$ Resultado de pesquisa do pós-doutorado da autora principal no Programa de Pós-graduação em Gestão Urbana (PPGTU/PUCPR), cujos indicadores foram validados junto às comunidades indígenas mapuches da região de Panguipulli (Sul do Chile) no projeto "Buen Vivir y Desarrollo a Escala Humana en pueblos originarios de Brasil y Chile" sob a coordenação de Manfred Max-Neef da Universidad Austral de Chile (UACh), ocorrido entre agosto e novembro de 2018. Ressalta-se a publicação de livro sobre o tema pela EdUFMT, em 2019, dos autores do artigo: "Bem viver e ecossocioeconomias".
} 
lidade de vida e Bem Viver passaram a ocupar centralidade nos debates ecológico e socioeconômico. Aprender a viver em sociedade, buscando o bem-estar e a qualidade de vida para todos é desafio ético da atualidade. Neste sentido, falar em qualidade de vida depende da incorporação e do exercício de princípios éticos por parte do Estado e da sociedade. "Questões axiológicas ou éticas [...] pertencem à busca por o que pode ser julgado como bom de acordo com um dado tempo e sociedade." (Almeida \& Schramm, 1999, p. 18, tradução nossa). Relativização dos valores éticos, bem como das legislações, falta de solidariedade e individualismo demonstram quão fragilizados estão estes conceitos que primam pelo bem coletivo.

O conceito de qualidade de vida começa por volta dos anos 60 , como uma alternativa à então dominante ideia de incrementar o nível de vida material. À vista da diminuição marginal da riqueza, dos limites do crescimento econômico e dos impactos sociais e ecológicos, foi-se incrementando a discussão (Cerda \& Vera, 2008, p. 11, tradução nossa).

Entretanto, o cunho multifatorial de qualidade de vida envolve aspectos políticos, econômicos e socioculturais, resultando em imprecisões teórico-metodológicas e de um consenso sobre o tema.

Os estudiosos da 'qualidade de vida' no mundo capitalista, apesar da quantidade de investigações realizadas, nunca estão completamente de acordo sobre o quê de fato esta qualidade de vida significa e como deve ser medida. Para a maioria, contudo, o termo 'qualidade' supõe a superação de uma limitada avaliação quantitativa do desenvolvimento (Campaña, 1997, p. 125).
Segundo Veenhoven (1988) apud Pena-Trapero $(2009$, p. 300 , tradução nossa), "a qualidade de vida se concebe como um amplo conceito que abarca três significados: 1) Qualidade do entorno em que vivemos; 2) Qualidade de ação; e 3) Desfrute subjetivo da vida". O bem-estar tem caráter multidimensional e encontra-se estreitamente vinculado a outros conceitos como qualidade de vida e felicidade.

Para Dolan et al. (2006, p. 14-16, tradução nossa), "há essencialmente cinco abordagens básicas para definir bem-estar". Listas objetivas, que "oferecem uma lista de atributos e características que são tomadas como constitutivas do bem-estar. Os conteúdos das listas variam, mas tendem a incluir itens tais como recursos econômicos, liberdade política, boa saúde e capacidade de ler". Satisfação de preferências, segundo a qual "a vida de um indivíduo vai melhor para ele se ele consegue o que quer". Considerações de realização, com menção a uma "versão perfeccionista de bem-estar em que o bem-estar de um indivíduo é julgado considerando quão perto estão de alcançarem o potencial da humanidade". Considerações hedônicas, que supõem a visão de que o prazer é a única coisa que é boa para nós, e dor é a única coisa que é má (Bentham, 1996). E considerações de avaliação, que "refletem os pesos que atribuímos a nossas experiências hedônicas ao longo de nossas avaliações de quão bem a vida está indo para nós de maneira mais geral". Desta forma, o bem-estar demonstra sua interface com a qualidade de vida no que tange à objetividade e subjetividade.

As perspectivas deste tipo identificam o bem-estar com características da vida como, por exemplo, o compromisso, o sentido, a virtude e a autenticidade; 
e muitas vezes acentuam também a forma em que o indivíduo se relaciona com as coisas do mundo (cumprimento de tarefas e relações com outras pessoas) (Abdallah, 2010, p. 33, tradução nossa).

Estas dimensões levaram a medições de níveis de bem-estar focados no indivíduo, requerendo novos constructos para uma avaliação multidimensional. Segundo Kahneman (2003, p. 15, tradução nossa), "os resultados que são geralmente considerados mais significativos para o bem-estar são estados relativamente estáveis, de riqueza, saúde, emprego, ou status familiar". Para Stiglitz et al. (2010) "as estatísticas comumente usadas podem não estar capturando alguns fenômenos, que têm um impacto crescente sobre o bem-estar dos cidadãos". Os indicadores de bem-estar aproximam-se do conceito de Bem Viver, apesar de sua complexidade e de suas múltiplas dimensões e pluralidades de unidades de análises e medidas. Os conteúdos deste conceito "apontam para transformações de fundo na sociedade, política, economia e na relação com a natureza" (Gudynas \& Acosta, 2011a, p. 106, tradução nossa). Os mesmos autores consideram, ainda, que:

Ao discutir metodologias para calcular de outra maneira e com renovados conteúdos outros índices econômicos, sociais e ambientais (quer dizer, do Bem Viver), avançar-se-á no projeto de novas ferramentas para tentar medir quão longe ou quão perto estamos da construção democrática de sociedades democráticas e sustentáveis. (Gudynas \& Acosta, 2011a, p. 109, tradução nossa).

Temas como interculturalidade e pluralidade de nacionalidades relacionam-se diretamente com o tema do Bem Viver. De um lado, a interculturalidade implica em diálogo entre culturas para avançar na transição que significa o Bem Viver, e para que "não termine predominando uma só visão, de maneira tal que se assimilem entre sociedades aqueles elementos conducentes a uma vida em harmonia entre seres humanos e com a natureza" (Pallaroso, 2014, p. 74, tradução nossa). De outro, o estado plurinacional - implantado na Bolívia e no Equador - "é fruto de um processo democrático que se iniciou com revoluções pacíficas, onde os povos [...] indígenas [...] reconquistaram gradualmente sua liberdade e dignidade" (Quadros de Magalhães \& Ribeiro, 2012, p. 200-201, tradução nossa). Soma-se a isto a participação, sobre a qual assinala Acosta (2008, p. 44, tradução nossa): "A construção de uma sociedade equitativa, igualitária e livre só será possível com o concurso de todos e de todas".

Quando se concebem indicadores sociais, sugere-se fazer as seguintes perguntas na ocasião em que se privilegia o paradigma de bem-estar social: "quem" (sujeitos ou coletivo a que se referem os indicadores), "o que" (conteúdos do bem-estar: nutrição, saúde, educação, trabalho...), "onde" (localização do bem-estar; questões da desigualdade espacial de oportunidades vitais do homem) e "como/por que" (quadro de hipóteses...) (Cerda $\&$ Vera, 2008).

\section{Indicadores subjetivos - além do PIB}

Um modo de considerar indicadores subjetivos é por meio do Índice de Felicidade Bruta (IFB). Proposto pelo Rei do Butão Jigme Singye Wangchuck em 1972, “[...] como resposta às críticas da constante pobreza econômica do país. [...]. O estudo realiza-se através de enquetes de percepção, 
construídas com uma matriz de 150 indicadores em que se integram as dimensões [...]" (Alaminos \& López, 2009, p. 23, tradução nossa). O IFB estabelece nove dimensões (entre parênteses, algumas de suas características): bem-estar psicológico (grau de satisfação e otimismo na vida individual), saúde (eficácia nas políticas de saúde), uso do tempo (estudo da gestão do tempo), vitalidade comunitária (analisa as relações e interações nas comunidades por meio da confiança, pertencimento, segurança), educação (educação das crianças e educação ambiental, entre outras), cultura (tradições locais), meio ambiente - mede a percepção dos cidadãos sobre a qualidade da água, ar, solo e biodiversidade), governo (percepção da comunidade em relação ao governo, sistema judicial), e qualidade de vida (renda familiar, dívidas contraídas, segurança no emprego) (Alaminos \& López, 2009)33.

$\mathrm{Na}$ década de 1990, iniciativa de Mahbub ul Haq, com colaboração de Amartya Sen, propõe-se o Índice de Desenvolvimento Humano (IDH), como resposta às críticas ao enfoque do crescimento centrado na economia. Trata-se de uma nova visão centrada nas pessoas, na melhoria da qualidade de vida e na participação social e econômica da comunidade, tanto em âmbito produtivo como na promoção do seu bem-estar. "O objetivo da criação do IDH foi o de oferecer um contraponto a outro indicador muito utilizado, o Produto Interno Bruto (PIB) per capita, que considera apenas a dimensão econômica do desenvolvimento" (PNUD, s.d.a). Pode-se dizer que o IDH é estruturado a partir de três pilares, apresentados na Tabela 1 .

Ao enfocar apenas em saúde, educação e renda (aspectos estes, sem dúvida, importantes em contexto de desenvolvimento), o IDH não leva em conta aspectos mais diretamente referentes à subjetividade de indivíduos, grupos e sociedades.

Com relação ao IDH tem-se assinalado a omissão de algumas oportunidades humanas fundamentais e, por isso, tem-se proposto incluir dimensões ou variáveis adicionais, em especial as referentes à liberdade, ao poder e à identidade cultural. Outros críticos sugerem incorporar a sustentabilidade e a equidade social. (Phélan, 2011, p. 82, tradução nossa).

TABELA 1 - Pilares de mensuração do Índice de Desenvolvimento Humano (IDH).

\begin{tabular}{lll}
\hline Pilar & Aspecto & Medida \\
\hline Saúde & Vida longa e saudável & - expectativa de vida \\
\hline Educação & Acesso ao conhecimento & $\begin{array}{l}\text { - média de anos de educação de adultos (número médio de anos de educação recebidos duran- } \\
\text { te a vida por pessoas a partir de 25 anos); }\end{array}$ \\
& $\begin{array}{l}\text { - expectativa de anos de escolaridade para crianças na idade de iniciar a vida escolar (número } \\
\text { total de anos de escolaridade que uma criança na idade de iniciar a vida escolar pode esperar } \\
\text { receber se os padrões prevalecentes de taxas de matrículas específicas por idade permanece- } \\
\text { rem os mesmos durante a vida da criança); }\end{array}$ \\
& & $\begin{array}{l}\text { Renda Nacional Bruta (RNB) per capita expressa em poder de paridade de compra (PPP) } \\
\text { constante, em dólar, tendo 2005 como ano de referência. }\end{array}$ \\
\hline Renda & Padrão de vida &
\end{tabular}

FONTE: Organizado pelos autores a partir de PNUD (s.d.b.).

\footnotetext{
${ }^{3}$ Alaminos \& López (2009, p. 29, tradução nossa) informam que "toda a informação relacionada com a composição do Índice foi extraída da página eletrônica http://www.felicidadeinternabruta.org.br ".
} 
Parece adequado incorporar, assim, a capacidade dos indivíduos em satisfazer as Necessidades Básicas Insatisfeitas (NBI) (Comisión Económica para América Latina y el Caribe - CEPAL (1988) face à importância que este conceito tem sobre o bem-estar destas pessoas. "O conceito de desenvolvimento humano nasceu definido como um processo de ampliação das escolhas das pessoas para que elas tenham capacidades e oportunidades para ser aquilo que desejam ser" (PNUD, s.d.a). Estes indicadores foram atualizados em 2010, quando se incluiu a taxa de alfabetização de adultos. Atualmente se inclui nesta dimensão a média do índice de escolarização e o índice de anos esperados de escolarização. No que diz respeito à riqueza, incluiu-se o índice de Renda Nacional per capita ao IDH, e somaram-se outros complementares de desenvolvimento humano (Tabela 2):

Nussbaum (2011) propõe que capacidades devem ser levadas em conta na dimensão do desenvolvimento humano como princípios de justiça social. Para a autora, enfrentam-se dificuldades para se medir capacidades. Em suas palavras: "Capacidades são plurais, mas isso não significa que cada uma delas não possam ser medidas isoladamente. A dificuldade é que a noção de capacidade combina preparação com oportunidade externa" (Nussbaum, 2011, p. 61, tradução nossa). Apesar de o IDH ser um índice que considera um leque de domínios mais amplos para o desenvolvimento que o PIB, ambos continuam indicando o crescimento como estratégia que se deve fomentar.

No Chile, Max-Neef, com a colaboração de Elizalde \& Hopenhayn (2012), em 1986, propõe o Desenvolvimento à Escala Humana - DEH, expondo uma compreensão da estrutura e dinâmica dos aspectos das atividades sociais denominada de "sistema econômico", a partir da perspectiva da atenção às necessidades humanas básicas, incluídas dentro do marco social e ecológico. De acordo com os autores, o melhor processo de desenvolvimento será aquele que permita garantir que as pessoas satisfaçam suas necessidades humanas, que são finitas, classificáveis e universais, promovendo qualidade de vida que lhe são próprias e apropriadas a seus territórios. De acordo com esta teoria, dividem-se em uma categoria existencial, cujas necessidades passam pelo Ser, Ter, Fazer e Estar; e uma cate-

TABELA 2 - Indicadores complementares de desenvolvimento humano.

\begin{tabular}{ll}
\hline Índice & Conceito \\
\hline $\begin{array}{l}\text { Índice de Desenvolvimento } \\
\text { Humano Ajustado à Desigualdade } \\
\text { (IDHAD) }\end{array}$ & $\begin{array}{l}\text { Leva em consideração a desigualdade em todas as três dimensões do IDH "descontando" o valor } \\
\text { médio de cada dimensão de acordo com seu nível de desigualdade. O IDH tradicional pode ser visto } \\
\text { como um índice de desenvolvimento humano "potencial" e o IDHAD como um índice do desen- } \\
\text { volvimento humano "real". }\end{array}$ \\
\hline $\begin{array}{l}\text { Índice de Desigualdade de Gênero } \\
\text { (IDG) }\end{array}$ & $\begin{array}{l}\text { Reflete desigualdades com base no gênero em três dimensões - saúde reprodutiva, autonomia e ati- } \\
\text { vidade econômica. A saúde reprodutiva é medida pelas taxas de mortalidade materna e de fertilidade } \\
\text { entre as adolescentes; a autonomia é medida pela proporção de assentos parlamentares ocupados por } \\
\text { cada gênero e a obtenção de educação secundária ou superior por cada gênero; e a atividade econô- } \\
\text { mica é medida pela taxa de participação no mercado de trabalho para cada gênero. }\end{array}$ \\
\hline $\begin{array}{l}\text { Índice de Pobreza } \\
\text { Multidimensional (IPM) }\end{array}$ & $\begin{array}{l}\text { Identifica privações múltiplas em educação, saúde e padrão de vida nos mesmos domicílios. As di- } \\
\text { mensões de educação e saúde se baseiam em dois indicadores cada, enquanto a dimensão do padrão } \\
\text { de vida se baseia em seis indicadores. }\end{array}$ \\
\hline
\end{tabular}

FONTE: Organizado pelos autores a partir de PNUD (s.d.b.). 
goria axiológica que compreende as necessidades de liberdade, proteção, afeto, entendimento, subsistência, participação, ócio, criação e identidade, que se desenvolvem em três dimensões: individual, coletiva e ecossistêmica, e que, para efeitos de diagnóstico e planificação podem cruzar-se em uma matriz.

Para Phélan (2011, p. 80, tradução nossa), o DEH “[...] é um exercício qualitativo que recolhe a visão subjetiva do desenvolvimento, sendo um caminho interessante para ser replicado em experiências em escala local, regional e nacional em uma aproximação ao estudo e à compreensão do Bem Viver" Desta forma, observa-se que esta teoria, cujo enfoque teórico se canaliza metodologicamente através da Matriz de NHF, possibilita o diagnóstico e avaliação do bem-estar por meio da subjetividade.

Em alguns estudos etológicos recentes têm sido distinguidos ao menos três significados para a noção de subjetividade, que com maior ou menor evidência parecem remeter às indicações originais da fenomenologia de Husserl e Scheler, [...]. O primeiro [...] revelaria o sentido de comunhão interpessoal entre sujeitos que mutuamente estão sintonizados em seus estados emocionais e em suas respectivas expressões. O segundo significado, reconhecível em estudos como os de Habermas (1970), compreende a intersubjetividade como aquela que define a atenção conjunta a objetos de referência em um domínio compartilhado de conversação linguística ou extralinguística. Como terceiro significado indica-se a capacidade de estabelecer-se inferências sobre intenções, crenças e sentimentos de outros, que envolveriam a simulação ou capacidade de "leitura" de estados mentais e processos de outros sujeitos, que de alguma forma nos remeteria ao clássico conceito de Einfühlung (empatia) (Coelho Junior \& Figueiredo, 2004, p. 13).
Os autores (2004) nos remetem ao contexto da transcendência quando se referem ao terceiro significado, reforçado no texto seguinte (Férnandez, 1994), como terceira realidade.

A estrutura da vida é uma estrutura de três nós, em que junto ao nu da realidade subjetiva individual e ao da realidade objetiva institucional, aparece uma realidade intersubjetiva $[. .$.$] . Frente à realidade do indivíduo \mathrm{e}$ frente à realidade das instituições sistêmicas, aparece pois uma realidade que não está dentro dos indivíduos, e de outra forma tampouco fora, senão entre os indivíduos e as instituições que não encarna nem em uns nem em outras, dos quais inclusive prescinde, nem tampouco nos grupos, senão que encarna em uma terceira natureza, não quantificável e impecavelmente real, feita de comunicação (Habermas, 1968; Rommetveit, 1974) quer dizer, de símbolos, significados e sentidos processando-se, e que a ninguém pertence mas que protagonizam todos os que pertencem a ela, e cujo sujeito é em primeira e última instância a coletividade. Esta é a terceira realidade, a do meio, a intersubjetividade, e é o lugar que corresponde às que alguma vez se chamaram ciências do espírito, entre as quais se conta a psicologia social (Fernández, 1994, p. 51, grifos da autora, tradução nossa).

Neste sentido, a definição da intersubjetividade "e a possibilidade de construir condições para a satisfação estejam limitadas às relações humanas de intersubjetividade e de reconhecimento recíproco que se consiga estabelecer" (Pérez Viramontes, 2010, p. 16, tradução nossa). Ou seja, a intersubjetividade permite aos indivíduos identificar suas necessidades e reclamar seu reconhecimento.

De acordo com a Comunicação da Comissão do Conselho e Parlamento Europeu (Comisión de las Comunidades Europeas, 2009, p. 6, tradução nossa), "os cidadãos se preocupam com sua qualidade de vida e seu bem-estar. A renda, os serviços 
públicos, a saúde, o lazer, a riqueza, a mobilidade e um entorno limpo são os meios para alcançar estes objetivos". Neste sentido, definem-se dimensões para medições de bem-estar:

Para definir o que bem-estar significa uma definição multidimensional tem que ser usada. Baseada em pesquisa acadêmica e em um número de iniciativas concretas desenvolvidas ao redor do mundo, a Comissão identificou as seguintes dimensões chave que devem ser levadas em conta. Pelo menos em princípio estas dimensões devem ser consideradas simultaneamente: i. Padrões de vida material (renda, consumo e riqueza); ii. Saúde; iii. Educação; iv. Atividades pessoais incluindo trabalho; v. Voz política e governança; vi. Conexões sociais e relações; viii. Meio ambiente (condições presentes e futuras); viii. Insegurança, de uma natureza econômica bem como física. Todas estas dimensões conformam o bem-estar das pessoas, e ainda muitas delas estão faltando em medidas de renda convencionais (Stiglitz et al., 2010 p. 14-15, tradução nossa).

\section{A Comunicación de la Comisión Europea} (2010) no documento "Europa 2020: uma estratégia para um crescimento inteligente, sustentável e integrador", propôs "para a UE (União Europeia) cinco objetivos quantificáveis para 2020 que marcarão a pauta do processo e se traduzirão em objetivos nacionais: o emprego, a pesquisa e a inovação, as mudanças climáticas e a energia, a educação e a luta contra a pobreza" (Barroso, 2010, p. 3, tradução nossa). Neste sentido, recompila-se, neste artigo, um conjunto que compreende desde indicadores tradicionais como o PIB até propostas mais recentes como indicadores sociais, ambientais e de bem-estar.

\section{A Comisión sobre la Medición del Desarrollo} Económico y Progreso Social, nomeada Stiglitz-Sen-Fitoussi (SSF), dispõe de uma relação de indicadores que pode ser resumida na Tabela 3 .

Estas dimensões caracterizam o bem-estar das pessoas, mas também apontam fragilidades de um sistema de indicadores e sua heterogeneidade, que muitas vezes não são levadas em conta nas mensurações convencionais. "Bem-estar subjetivo abrange diferentes aspectos (avaliações cognitivas da vida de alguém, felicidade, satisfação; emoções positivas tais como alegria e orgulho e emoções negativas tais como dor e preocupação)" (Stiglitz et al., 2010, p. 18, tradução nossa).

Gudynas (2011) apresenta propostas que procuram romper com as ideias comumente aceitas de desenvolvimento como crescimento e progresso (Tabela 4).

Para o citado autor, no nível A, "o primeiro grande conjunto de 'desenvolvimentos alternativos' expressa as discussões que se dão entre as grandes correntes de pensamento contemporâneas," [...] com foco "em questões tais como o papel do Estado no desenvolvimento, as formas de intervenção (ou não) no mercado, [...]"; o segundo conjunto - nível $\mathrm{B}$ - "corresponde às 'alternativas de desenvolvimento', [...] destacando-se a reflexão de Ivan Illich $^{4}[\ldots]$ na proposta da habilidade de conviver". "Outras contribuições importantes provêm do feminismo, $[\ldots]$ mudanças nos padrões de consumo

\footnotetext{
4 "Habilidade de conviver entende-se como o inverso da produtividade industrial. [...] A relação de convivência [...] é ação de pessoas que participam na criação da vida social. Transladar-se da produtividade à habilidade de conviver é substituir um valor técnico por um valor ético, um valor material por um valor realizado (Illich, 2006)" (Gudynas, 2011, p. 48, n. r. nº 12, tradução nossa).
} 
TABELA 3 - Recomendações do Informe Stiglitz-Sen-Fitoussi.

Recomendações relativas ao bem-estar material
- Quando a avaliar bem-estar material, olhar para renda e consumo ao invés de para produção; Enfatizar a perspectiva doméstica;

- Considerar renda e consumo junto com riqueza;

- Dar mais proeminência à distribuição de renda, consumo e riqueza.

- Ampliar medidas de renda a atividades externas ao mercado.

Recomendações relativas ao bem-estar e qualidade de vida

Recomendações relativas ao âmbito do meio ambiente e a sustentabilidade

- Qualidade de vida depende das condições objetivas e capacidades das pessoas. [...].

- Indicadores de qualidade de vida em todas as dimensões consideradas deveriam avaliar desigualdades de maneira abrangente;

- Levantamentos devem ser projetados para acessar as ligações entre vários domínios da qualidade de vida para cada pessoa, e esta informação deveria ser usada quando projetaremse políticas em vários campos;

- Agências de estatística devem fornecer a informação necessária para agregar através de dimensões de qualidade de vida, permitindo a construção de diferentes índices.

- Medidas de bem-estar tanto objetivo como subjetivo fornecem informação chave sobre a qualidade de vida das pessoas. [...]

- Levantamento de sustentabilidade requer um quadro bem definido de indicadores. [...]
- Os aspectos ambientais da sustentabilidade merecem um acompanhamento especial baseado em um bem conhecido conjunto de indicadores. [...]

- Levantamento de sustentabilidade requer um quadro secundário bem definido do quadro global a ser recomendado pela Comissão.

- A característica distintiva de todos os componentes desse quadro secundário deveria ser informar sobre variações daqueles "estoques" que sustentam o bem-estar humano.

- Um índice monetário de sustentabilidade tem seu lugar em tal quadro, mas sob o atual estado da arte, deveria permanecer essencialmente focado em aspectos econômicos da sustentabilidade.

- Os aspectos ambientais da sustentabilidade merecem um acompanhamento separado baseado em um conjunto bem escolhido de indicadores físicos.

FONTE: Stiglitz et al. (2010, tradução nossa).

TABELA 4 - Classificação provisória de desenvolvimentos alternativos e alternativas ao desenvolvimento.

\section{A) Alternativas dentro da ideologia do progresso e da modernidade}

Alternativas instrumentais clássicas

Reparação dos efeitos negativos (e.g. reformismo social-democrata, "terceira via"), desenvolvimento nacional popular, novo desenvolvimentismo, novo extrativismo progressista.

Alternativas enfocadas nas estruturas e nos processos econômicos e no papel do capital
Alternativas socialistas, estruturalismo inicial, marxistas e neomarxistas, dependistas, novo estruturalismo, vários expoentes do socialismo do século XXI. 
Limites sociais do crescimento, dissociação entre economia e desenvolvimento, ênfase em emprego e pobreza.

Desenvolvimento endógeno, desenvolvimento humano, desenvolvimento à escala humana.

Outras economias (doméstica, informais, camponesa, indígena), multiculturalismo liberal.

Alternativas que reagem aos impactos ambientais

Ecodesenvolvimento, sustentabilidade fraca e parte da sustentabilidade forte $^{5}$.

\title{
B) Alternativas mais além do progresso e da modernidade
}

- $\quad$ Afeição à convivência.

- Desenvolvimento sustentável superforte ${ }^{6}$, biocêntricos, ecologia profunda ${ }^{7}$.

- Crítica feminista, economia do cuidado ${ }^{8}$.

- Desmaterialização das economias, decrescimento (em parte).

- Interculturalismo, pluralismo, ontologias reacionais, cidadanias expandidas.

- $\quad$ Bem viver (algumas manifestações).

FONTE: Gudynas (2011, p. 47, tradução nossa).

\begin{abstract}
5 "Para a visão da sustentabilidade fraca (Sfra), $K$ [capital] tem como crescer de forma quase ilimitada, basicamente porque considera que $K p$ [capital produzido] e Kn [capital natural] podem, com facilidade, substituir um ao outro. [...] Essa visão tende a prevalecer na corrente da economia do meio ambiente que emanou diretamente da análise econômica convencional: a da economia ambiental neoclássica. Já a visão da sustentabilidade forte (Sfor) é bem menos otimista em relação ao desenvolvimento sustentável, pois considera limitada a substitutabilidade [sic] entre Kp e Kn. Aceita que, até certo ponto, esta existe, mas considera que se o crescimento for acompanhado de escassez relativa cada vez maior de capital natural ele poderá ser inviabilizado." (Mueller, 2005, p. 702-703, grifos do autor).

6"A sustentabilidade superforte sustenta que o ambiente deve ser valorizado de muitas diferentes maneiras, além da economia: também existem valores culturais, ecológicos, religiosos ou estéticos, que são tanto ou mais importantes" (Gudynas, 2009, p. 15-16, grifo do autor, tradução nossa).

${ }^{7}$ A ecologia profunda enquanto "escola filosófica foi fundada pelo filósofo norueguês Arne Naess, no início da década de 1970, com sua distinção entre 'ecologia rasa' e 'ecologia profunda'. [... .] A ecologia rasa é antropocêntrica, ou centralizada no ser humano. Ela vê os seres humanos como situados acima ou fora da natureza, como a fonte de todos os valores, e atribui apenas um valor instrumental, ou de 'uso', à natureza. A Ecologia profunda não separa seres humanos - ou qualquer outra coisa - do meio ambiente natural. Ela vê o mundo não como uma coleção de objetos isolados, mas como uma rede de fenômenos que estão fundamentalmente interconectados e são interdependentes. A ecologia profunda reconhece o valor intrínseco de todos os seres vivos e concebe os seres humanos apenas como um fio particular na teia da vida." (Capra, 2006, p. 25).
\end{abstract}

${ }^{8}$ Adota-se aqui uma noção de economia do cuidado derivada de parte da ênfase que M. Daly e J. Lewis identificam no conceito de cuidado social: “atividades e relações envolvidas em satisfazer as necessidades físicas e emocionais de crianças e adultos dependentes” (Daly \& Lewis, 2000, p. 285, tradução nossa). 
e estilos de vida." e "finalmente, [...] de recuperar algumas das posturas e cosmovisões dos povos indígenas" (Gudynas, 2011, p. 47-49, tradução nossa). Deste modo, procura-se sair da instrumentalidade para uma visão sistêmica e multidimensional no contexto do Bem Viver.

\section{Resultados e discussões}

A Carta Magna de 2008 do Equador é categórica a respeito dos princípios gerais de desenvolvimento e sua relação com os demais direitos, nos termos do parágrafo segundo de seu artigo 275 , a seguir transcrito: "O bem viver requererá que as pessoas, comunidades, povos e nacionalidades gozem efetivamente de seus direitos, e exerçam responsabilidades no marco da interculturalidade, do respeito a suas diversidades, e da convivência harmônica com a natureza" (Ecuador, s.d., tradução nossa). O Plan Nacional para el Buen Vivir 2013-2017 (Ecuador, 2013) menciona uma série de características que esboçam um indicador de qualidade, como:

(i) precisos e relevantes, posto que permitem medir trocas atribuíveis às políticas públicas; (ii) confiáveis e transparentes, em razão de que distintos avaliadores obtêm os mesmos resultados; (iii) periódicos, para conhecer e avaliar sua tendência no tempo; e (iv) de impacto, porque permitem ver as trocas no bem-estar da população (Ecuador, 2013, p. 18, grifos do autor, tradução nossa).
Além disso, o Plan Nacional para el Buen Vivir 2013-2017 (Ecuador, 2013, p. 29, tradução nossa) aponta "seis dimensões básicas para o planejamento, o seguimento e a avaliação do processo encaminhado ao Bem Viver no Equador:" diversificação produtiva e segurança econômica, acesso universal a bens superiores ${ }^{9}$, equidade social, participação social, diversidade cultural, e sustentabilidade. Além de indicar a prioridade de investimento "à geração de capacidades e à redução das brechas sociais e territoriais" (Ecuador, 2013, p. 17, tradução nossa).

Apesar deste empenho, como gerador de recursos para acabar com as iniquidades e elevar a qualidade de vida, o modelo de desenvolvimento assinalado pelo Plano não é suficiente. Ou seja, aspira-se contar com uma nova medida que permita avaliar os avanços da ação pública na direção do Bem Viver. Os princípios da Constituição equatoriana de 2008 e do Plan Nacional para el Buen Vivir 2013-2017, apesar de enunciarem algumas garantias envolvendo indicadores referentes a direitos sociais e econômicos, necessitam de maior precisão no que diz respeito a direitos políticos, coletivos, ambientais e de liberdade. No que se refere à distribuição e rendimentos e à acumulação, há a seguinte observação:

Do extrativismo de origem colonial, praticado sem maiores mudanças pelos governos neoliberais, transitou-se a um neoextrativismo que tem alguns pontos recuperáveis, como o maior controle do estado sobre as atividades extrativistas e a distribuição de seus rendimentos, mas que não se distancia de uma modalidade de acumulação dependente e subdesenvolvedora. (Acosta, 2016, p. 234).

\footnotetext{
${ }^{9}$ Bens superiores referem-se a "saúde, educação, trabalho digno, habitação, [...] tempo destinado a viver em plenitude e à provisão de bens relacionais (amizade, amor, solidariedade, coesão social)”. (Ecuador, 2013, p. 29, tradução nossa).
} 
Na Constituição do Equador, o Bem Viver/Buen Vivir é apresentado como um direito que contempla água e alimentação, ambiente saudável, comunicação e informação, cultura e ciência, educação, habitat e moradia, saúde, trabalho e seguridade social (Ecuador, s.d.), e que permite identificar correspondências entre eles e o sumak kawsay. Segundo Hidalgo Capitán (2012a, p. 16; 2012b, p. 49), no Equador existem três correntes do Bem Viver: (1) indigenista/ pachamamista; (2) socialista/estadista; e (3) pós-desenvolvimentista/ecologista, citadas anteriormente.

De outro lado, na Constituição Política do Estado Plurinacional da Bolívia, promulgado em 2009, as referências ao Viver Bem/Vivir Bien aparecem no título sobre as bases fundamentais do Estado onde se abordam os princípios, valores e fins do Estado (art. 8), em que o Estado assume e promove princípios ético-morais de uma sociedade plural (Bolivia, 2008).

Estes princípios do Bem Viver se apresentam em paralelo, e com a mesma hierarquia, que outros princípios clássicos, tais como unidade, igualdade, inclusão, dignidade, liberdade, solidariedade, reciprocidade, respeito, equidade social e de gênero na participação, bem-estar comum, responsabilidade, justiça social etc. (também incluídos no artigo 8) (Gudynas \& Acosta, 2011b, p. 77, tradução nossa).

O modelo boliviano está orientado a melhorar a qualidade de vida e Viver Bem dos cidadãos. No caso da Bolívia, observa-se uma maior amplitude cultural, enquanto se postulam concepções do Bem Viver de várias tradições indígenas além da aimara, tais como o quéchua e o guarani.

Estabelece-se então constitucionalmente que são fins essenciais do Estado constituir uma sociedade justa e harmoniosa cimentada na descolonização, sem discriminação nem exploração, com plena justiça social, para consolidar as identidades de uma pluralidade nacional. Garantir também a proteção e a dignidade das nações, os povos e as comunidades, e fomentar o respeito mútuo e o diálogo intercultural e plurilíngue. Estabelece a diversidade de uma pluralidade nacional e neste sentido a necessidade de repensar os aspectos concernentes à educação, a saúde, a produção, mas sempre velando pelo equilíbrio da Mãe Terra (Pachamama) (Mamani, 2010, p. 19, tradução nossa).

Apesar de sua formulação ser mais recente que a do Equador, o reconhecimento de vida buena remete aos conceitos análogos defendidos nos povos indígenas.

Se na Bolívia o Viver Bem remete aos direitos cidadãos tradicionais, para Gudynas, no Equador, o conceito referiria também a outras concepções do direito. Se na Bolívia e em outros países a natureza é salvaguardada por sua importância para os humanos, no Equador haveria um reconhecimento de direitos aos ciclos vitais de restauração (seriam direitos ecológicos, mais além dos tradicionais "ambientais") (Schavelzon, 2015, p. 253, tradução nossa).

A relação com a natureza é um aspecto chave para a construção do Bem Viver. Nas questões ambientais a Constituição do Equador oferece uma postura biocêntrica e reconhece a Natureza como sujeito de direitos (arts. de 71 a 74) (Ecuador, s.d.). Já no texto da Bolívia alguns artigos defendem o mandato do Estado para industrializar os recursos naturais com ideias clássicas do progresso baseadas na apropriação da Natureza (art. 9) (Bolivia, 2008). Outras questões também se fazem presentes:

[...] No caso da Bolívia, o suma qamaña e os demais conceitos associados são princípios ético-morais 
e não aparecem como direitos, tal como sucede na Constituição equatoriana. Estão enfocados em delimitar os marcos para uma sociedade que se define como plural em termos de nacionalidades. Inclusive se pode argumentar que estes princípios ético-morais seriam uma das fundamentações dessa pluralidade de nacionalidades, e o Bem Viver é então uma condição que pode expressar-se de diferente maneira em cada uma delas. Na Constituição do Equador, em vez disso, o sumak kawsay é apresentado em dois níveis: como o marco para um conjunto substantivo de direitos, e como expressão de boa parte da organização e execução desses direitos, não só no Estado, mas também em toda a sociedade (Gudynas \& Acosta, 2011b, p. 78, tradução nossa).

Percebem-se algumas aproximações entre as duas Constituições, como a ideia do Bem Viver diretamente vinculada aos saberes e tradições indígenas e a busca de "outro" desenvolvimento. Ambas buscam a construção de uma sociedade menos mercantilizada. Acosta \& Gudynas (2011) sustentam que a construção do conceito do Bem Viver também está presente nas tradições ocidentais que criticaram distintos preceitos da modernidade. "Entre elas se encontram posturas éticas alternativas que reconhecem os direitos da natureza, as contribuições do feminismo como reação à dominação de base patriarcal e as novas conceptualizações em área como a justiça e o bem-estar humano" (Acosta \& Gudynas, 2011, p. 74, tradução nossa).

Considerando a multidimensionalidade do conceito do Bem Viver e seu pluralismo metodológico, é trazida a este texto a manifestação de Alaminos \& López (2009) no sentido de que este conceito incorpora elementos subjetivos. Esses autores consideram que "[...] o acesso do sujeito (sociedade) à interpretação do conceito obriga-nos a empregar a distinção entre a perspectiva Etic e a perspectiva Emic. A perspectiva Emic remete-nos à visão que os indivíduos têm de sua própria vida. As motivações e as razões que empregam para explicar-se a si mesmos e aos demais" (Alaminos \& López, 2009, p. 13, tradução nossa). Na perspectiva Emic, há um componente subjetivo importante, "um narrador interno diegético que conta e protagoniza sua própria história vital" (Alaminos \& López, 2009, p. 13, tradução nossa). A perspectiva Etic é de caráter objetivo sobre a qual se manifesta. A esfera da ética transcende o mundo do sujeito, isto é, rediscute-se a ação moral, da microescala a partir da macroescala. De acordo com esse raciocínio, em vez de representar um dilema, a utilização de ambas as abordagens aprofunda a compreensão sobre questões importantes na pesquisa científica e na investigação em modelagem étnica ${ }^{10}$.

\subsection{Construção de indicadores do bem viver}

A proposta do Bem Viver foi concebida a partir de uma cosmovisão andina, a qual incorpora a ideia de bem-estar, natureza como sujeito de direito e uma convivência em harmonia e equilíbrio. O Plano Nacional para o Bem Viver, do Equador, "propõe uma visão do Bem Viver que amplia os direitos, liberdades, oportunidades e potencialidades dos seres humanos, comunidades, povos e nacionalidades, e que garante o reconhecimento das diversidades para alcançar

\footnotetext{
10 "A etnomodelagem considera o conhecimento adquirido a partir das práticas matemáticas utilizadas no grupo cultural ou na comunidade" (Rosa \& Orey, 2012, p. 868).
} 
um porvir compartilhado" (Ecuador, 2009, p. 33, tradução nossa).

Frente a esta proposta e às argumentações apresentadas, tem-se como desafio de conceber medidas de Bem Viver que compreendam a noção indígena de Sumak Kawsay (Buen Vivir da Constituição equatoriana de 2008) ou Suma Qamaña (Vivir Bien na Bolívia), e que ainda sejam coerentes com o contexto internacional.

O Bem Viver ainda sendo, como alguns autores assinalam, um conceito em construção, precisa de sua operacionalização por duas razões fundamentais. A primeira de ordem metodológica “... para poder medir fará falta definir e que a definição poderá ser favorecida pelas intenções de medição. Isso é o que se quer dizer com o "caminhar com os dois pés". Nem a "grande teoria" nem o "empirismo abstrato" senão apoio mútuo entre definição e medida." (Tortosa, 2009, p. 17). É uma maneira de aproximar-nos da conceptualização. A segunda razão tem a ver com sua colocação em prática para poder orientar a implementação das ações públicas, como o rastreamento, a avaliação e a análise (Arias \& Phélan, 2016, grifo do texto original, tradução nossa).

Este enfoque está centrado na autonomia e no desenvolvimento do indivíduo e do coletivo de maneira que possam desenvolver as destrezas e habilidades de sua preferência.
O Bem Viver, como uma nova maneira de organizar a sociedade, visto a partir desta perspectiva, implica a expansão das potencialidades individuais e coletivas, que nós devemos descobrir e fomentar. Não há que se desenvolver à pessoa, a pessoa tem que se desenvolver. Para consegui-lo, como condição fundamental, qualquer pessoa há de ter as mesmas possibilidades de eleição, ainda que não tenha os mesmos meios. O Estado corrigirá as deficiências dos mercados e atuará como promotor da troca, nos campos que seja necessário (Acosta, 2010, p. 34, tradução nossa).

Apesar de o paradigma em construção do Bem Viver surgir como proposta que emerge dos problemas de equidade social e devastação ambiental, encontra-se em um processo de construção, tanto no que diz respeito à contextualização como na operacionalização do seu conceito. Emerge a necessidade de conceber uma proposta de indicadores que possa transitar entre objetividade e subjetividade, a partir da multidimensionalidade que é inerente ao território e a sua singularidade. Neste artigo, propõe-se que essas qualidades sejam contempladas conforme apresentadas na Tabela 5 .

Neste estudo, a intersubjetividade presente no Bem Viver transcende o valor instrumental do Bem-Estar e o da Qualidade de Vida. É formada por símbolos, significados e sentidos coletivos

TABELA 5 - Indicadores.

\begin{tabular}{lll}
\hline Indicadores & Dimensões cognitivas & Predominância na modalidade de dados \\
\hline Qualidade de vida & Objetividade & Quantitativa \\
\hline Bem Estar & $\begin{array}{l}\text { Maior subjetividade e menor } \\
\text { objetividade }\end{array}$ & Qualiquantitativa \\
\hline Bem Viver & Intersubjetividade e objetividade & Qualiquantitativa \\
\hline
\end{tabular}

FONTE: Os autores. 
que não pertencem unicamente a alguém, mas a toda a sociedade. Representa um processo "ancorado na ética" (Freire, 2001, p. 146), com tendência a construir relações que conduzam por sua vez ao reconhecimento universal das necessidades humanas. Ao mesmo tempo, nas três correntes equatorianas apontadas neste estudo destacam-se parâmetros fundamentais na concepção de indicadores do Bem Viver com propostas e princípios de igualdade e reciprocidade (Hidalgo-Capitán, 2012a). Ou seja, a definição de Bem Viver abordada por estas três correntes perpassa cosmovisão indígena, socialismo moderno e alternativa ao desenvolvimento, o que denota multidimensionalidade.

Enfatiza-se assim a proteção da natureza por meio dos direitos da Madre Tierra e da "construção participativa do Bem Viver" (Hidalgo-Capitán \& Cubillo-Guevara, 2014, p. 28, grifo dos autores, tradução nossa). Ademais, considera-se, aqui também, que "um dos pontos mais importantes desta interpretação é a ideia de que o Bem Viver não pode ser considerado uma ideia linear de progresso, $[\ldots]$ cada comunidade tem que viver sob os princípios de seu próprio Bem Viver" (Torres, 2015, p. 220, tradução nossa).

Igualmente, levou-se em conta a proposição da existência de três dimensões que deveriam formar a base da proposta do Bem Viver: "os pobres resultados do desenvolvimento em termos de equidade social, a deficiente articulação entre crescimento econômico e melhoramento na qualidade de vida, e os limites estruturais para assegurar a sustentabilidade" (Ecuador, 2013, p. 22, tradução nossa). Para Phélan \& Guillén (2012, p. 183, tradução nossa) "este é um desafio que por certo não é fácil, se se quer transformar um conceito em processo de construção em um conjunto de indicadores ou em um índice sintético".

Uma tal proposta do Bem Viver, ao questionar os tradicionais conceitos do chamado desenvolvimento, convoca a construir sistemas de indicadores próprios que constituem uma grande oportunidade para denunciar as limitações e falácias dos sistemas de indicadores dominantes [...] e também para discutir metodologias de medição de outra maneira e de renovados conteúdos de outro desenvolvimento (quer dizer, do Bem Viver). Isso permitirá avançar no projeto de novas ferramentas que intentem medir quão longe ou quão perto estamos de uma construção democrática de sociedades democráticas e sustentáveis. (Acosta, 2011, p. 194, tradução nossa).

Na definição de indicadores em cada dimensão, extraíram-se alguns que sugerem utilidade para a medição das dimensões do Bem Viver, buscando uma complementaridade entre subjetivo e objetivo, interculturalidade, multidimensionalidade, dimensão participativa e territorial (Tabela 6).

Frente aos limites conceituais e operativos, entende-se que o êxito e os desdobramentos em torno da matriz de indicadores do Bem Viver não conduzem a um conceito único, mas plural, resultante de coerência conceitual, participação dos cidadãos e transparência metodológica, chaves para elaboração de um processo participativo de planejamento de políticas com propostas para além do desenvolvimento em sua concepção clássica. 
TABELA 6 - Matriz de indicadores de Bem Viver ${ }^{11}$.

\begin{tabular}{|c|c|c|c|}
\hline \multicolumn{4}{|c|}{ Matriz de Indicadores de Bem Viver } \\
\hline Supra Dimensões & Dimensões Específicas & Indicadores/Atributos & Conceitos \\
\hline \multirow{6}{*}{$\begin{array}{l}\text { Pessoal (harmonia consigo } \\
\text { mesmo) }\end{array}$} & Habitação & $\begin{array}{l}\text { Condições da moradia } \\
\text { Acesso à água segura: potável, nascentes } \\
\text { ou poços artesianos } \\
\text { Rede de esgoto } \\
\text { Superlotação (número de pessoas por } \mathrm{m}^{2} \text { ) } \\
\text { Acesso a saneamento básico } \\
\text { Espaço para dormir } \\
\text { Segurança alimentar } \\
\text { Alimentação diária consumida } \\
\text { Acesso à eletricidade }\end{array}$ & $\begin{array}{l}\text { Satisfação com a moradia e as } \\
\text { condições de infraestrutura, } \\
\text { como acesso a água potável, } \\
\text { energia elétrica e alimentação } \\
\text { (segurança alimentar) }\end{array}$ \\
\hline & Trabalho & $\begin{array}{l}\text { Trabalho/ocupação } \\
\text { Acesso à segurança social } \\
\text { Situação financeira } \\
\text { Renda mensal recebida pela família } \\
\text { Horas diárias dedicadas ao trabalho }\end{array}$ & $\begin{array}{l}\text { Satisfação com o trabalho/ } \\
\text { ocupação exercida; acesso a } \\
\text { segurança social; satisfação } \\
\text { financeira }\end{array}$ \\
\hline & Religião e Crenças & $\begin{array}{l}\text { Crenças espirituais, religiosas ou filosó- } \\
\text { ficas } \\
\text { Participação em instituições religiosas }\end{array}$ & $\begin{array}{l}\text { Grau de satisfação com sua } \\
\text { crença espiritual }\end{array}$ \\
\hline & Tempo Livre e Cultura & $\begin{array}{l}\text { Uso do tempo livre } \\
\text { Espaços para a recreação e cultura } \\
\text { Jogos e atividades ao ar livre }\end{array}$ & $\begin{array}{l}\text { Satisfação com o tempo livre, } \\
\text { jogos e atividades comunitárias }\end{array}$ \\
\hline & Recursos Materiais & $\begin{array}{l}\text { Ajuda econômica (financiamento) } \\
\text { Venda da produção (ganhos efetivos/ } \\
\text { mensal) }\end{array}$ & $\begin{array}{l}\text { Satisfação financeira; renda } \\
\text { mensal recebida. Financiamen- } \\
\text { tos e ajuda de custo }\end{array}$ \\
\hline & $\begin{array}{l}\text { Tecnologias de Informa- } \\
\text { ção e Comunicação }\end{array}$ & $\begin{array}{l}\text { Disponibilidade de Internet } \\
\text { Disponibilidade de telefone convencional } \\
\text { Disponibilidade de celular }\end{array}$ & $\begin{array}{l}\text { Acesso à informação e comu- } \\
\text { nicação }\end{array}$ \\
\hline
\end{tabular}
${ }^{11}$ No intuito de identificar as variáveis e os níveis de satisfação, por meio desta matriz de indicadores, propõe-se operacionalizar a pesquisa a
partir do debate das comunidades no contexto de um diagnóstico participativo com graus de satisfação negativos e positivos de cada dimensão. 
Comercialização dos produtos agrícolas/ pecuários/artesanatos/outros

Fatores Produtivos

Acesso a sistemas de irrigação

Capacitação recebida para exercer atividade

econômica que realiza

Diversidade de culturas

Acesso a sementes

Participação em Organizações Sociais

Poder de decisão

Participação

Participação em Organizações Sociais:

Associações

Participação em reuniões comunitárias

Sistema de governança

Social (harmonia com a comunidade integral)

Sistema de governança

\begin{tabular}{lll}
\hline Família & $\begin{array}{l}\text { Satisfação com sua situação familiar } \\
\text { Permanência dos jovens na comunidade }\end{array}$ & $\begin{array}{l}\text { Satisfação com a vida familiar e } \\
\text { o êxodo dos jovens }\end{array}$ \\
\hline \multirow{2}{*}{ Segurança } & $\begin{array}{l}\text { Segurança familiar } \\
\text { Frequência de assaltos na comunidade } \\
\text { Policiamento na comunidade } \\
\text { Justiça com as próprias mãos }\end{array}$ & $\begin{array}{l}\text { Satisfação com a segurança } \\
\text { individual e familiar na comu- } \\
\text { nidade }\end{array}$ \\
\hline
\end{tabular}

Participação da mulher e dos jovens nas atividades econômicas

Trabalho/renda

Empoderamento

Relações de Gênero e

Jovens

Acesso a crédito

Poder de decisão

Taxa de matriculas no ensino (combinando

educação primária, secundária e superior)

Conciliação do aleitamento materno com o

trabalho
Participação da mulher e dos jovens nas atividades produtivas, trabalho e renda, participação nas decisões.
Satisfação com os fatores produtivos, como diversidade de culturas e comercialização

Participação social; Poder de decisão e escolha, Arranjos Produtivos Locais (APLs)
Saúde

\section{Integral (harmonia com a} natureza)
Serviços de saúde (posto de saúde/hospital) Tratamento Médico e enfermaria Condições de acesso a tratamento profissional

Uso de plantas medicinais

Satisfação com a saúde das pessoas

Distância dos centros de saúde
Variáveis como distância do posto de saúde ou hospital, infraestrutura de saúde, qualidade dos profissionais da saúde
Meio Ambiente

Uso de queimadas

Qualidade do ar respirado

Meio ambiente, entorno natural

Uso de agrotóxicos e pesticidas

Nascentes de água

Preservação da mata nativa

Emissão per capita de $\mathrm{CO}_{2}$

Práticas ecológicas com resíduos (reciclagem, compostagem, artesanato, outros)

Identidade com o lugar

Pertencimento
Sentimento de compromisso

Tranquilidade
Satisfação com o meio ambiente; Práticas ambientais; uso de agrotóxicos; preservação ambiental.

FONTE: Os autores, com base em Sen (2000); NEF (2009); Comissão Europeia (2009); Stiglitz et al. (2010), Gudynas (2011); Max-Neef (2012); León (2015). 


\section{Considerações gerais}

No estudo de diferentes correntes de desenvolvimento observou-se que, nas últimas décadas, muitas vêm acompanhadas de um conjunto de indicadores sociais, econômicos e ambientais. Neste contexto, o Bem Viver tem sido colocado como uma alternativa ao desenvolvimento hegemônico, a partir do saber ancestral dos povos indígenas e chegando até a sociedade atual, como uma forma de superação de problemas gerados pelo capitalismo neoliberal.

Apesar dos desafios e das críticas envolvidos na medição do bem-estar subjetivo por meio de indicadores de Bem Viver, procurou-se trazer alguns aportes à discussão, transitando entre as dimensões objetiva e subjetiva do conceito, considerando a complexidade e a multidimensionalidade do conceito do Bem Viver. Considerou-se o conjunto de contribuições referentes a bem-estar e qualidade de vida das métricas dos indicadores nas dimensões econômicas, sociais, culturais, ambientais, de direitos civis e política que, em cada cultura em particular, se consideram-se relevantes.

Esta proposta avança em relação à Matriz de Necessidades e Elementos de Satisfação, de Max-Neef (2012); ou em relação às Recomendações do Informe Stiglitz et al., (2010) e outros que embasaram esta matriz, no que tange à intersubjetividade transcendental (dimensão da crença espiritual), saindo do materialismo para a interculturalidade, implicando em um diálogo entre as culturas e entre ser humano e natureza, rompendo o discurso hegemônico entre mercado e natureza humana.
O levantamento de indicadores de Bem Viver poderá servir de análise a modalidades de experiências ecológicas e socioeconômicas e/ou ecossocioeconomias $^{12}$ no Brasil e no mundo. Espera-se que a aplicação da matriz nas comunidades possa levar à formulação de políticas públicas concretas organizadas nos próprios territórios, emancipatórias e promotoras de direitos sociais, no que diz respeito a questões éticas e educacionais, saúde, valorização de formas de vida tradicionais, economia social e solidária, relações de gênero, geração de trabalho e renda e outras.

Deste modo, sugere-se avaliar necessidades que transcendam abordagens dicotômicas e instrumentais ao inter-relacionar aspectos psicossociais vinculados ao reconhecimento e a intersubjetividade (autonomia, empatia, emoções, segurança, relacionamento com o outro, autoconfiança, etc). Dimensões estas que nunca devem ser impostas, mas construídas por meio do consenso democrático e da ética discursiva a partir da práxis individual e intersubjetiva.

\section{Referências}

Abdallah, S. La revolución del bienestar. CIP-Ecosocial - Boletín ECOS, 11, 1-12, 2010. Disponível em: $<$ https://www.fuhem.es/media/cdv/file/biblioteca/Boletin_ECOS/11/la_revolucion_del_bienestar.pdf $>$. Acesso em: 21 jun. 2019.

Acosta, A. E. El buen vivir en el camino del post-desarrollo: Una lectura desde la Constitución de Montecristi. Policy Paper, 9, 2010. Disponível em: <http://library.fes.de/pdf-files/bueros/quito/07671.pdf>. Acesso em: 23 out. 2018.

\footnotetext{
${ }^{12}$ São alternatividades que "ocorrem no mundo da vida, nas experiências empíricas nas comunidades, povoados, onde os problemas e as soluções acontecem e nem sempre são devidamente qualificados” (Alcântara \& Sampaio, 2017, p. 240).
} 
Acosta, A. E. El buen vivir, una oportunidad por construir. Ecuador Debate, 75, 33-48, 2008.

Acosta, A. E. O bem viver. São Paulo: Autonomia Literária/ Elefante, 2016. 264 p.

Acosta, A. E. Sólo imaginando otros mundos, se cambiará éste. In: Farah H. I.; Vasapollo, L. (Coords.). Vivir bien: ¿Paradigma no capitalista? La Paz: Plural, 2011. p. 189-208.

Acosta, A. E.; Gudynas, E. El buen vivir mas allá del desarrollo. Queacer, 181, 70-81, 2011. Disponível em: <http:// www.desco.org.pe/recursos/sites/indice/807/2361.pdf > . Acesso em: 23 jun. 2019.

Alaminos, A.; López, B. La medición del desarrollo social. OBETS: Revista de Ciencias Sociales, 4, 11-24, 2009. Disponível em: $<$ https://rua.ua.es/dspace/bitstream/10045/13390/1/Obets_4_02.pdf $>$. Acesso em: 23 jun. 2019.

Alcântara, L. C. S.; Sampaio, C. A. C. Bem viver como paradigma de desenvolvimento. Desenvolvimento e Meio Ambiente, 40, 231-251, 2017. doi: 10.5380/dma.v40i0.48566

Almeida, J. L. T.; Schramm, F. R. Paradigm shift, metamorphosis of medical ethics, and the rise of bioethics. Cadernos de Saúde Pública, 15(1), 15-25, 1999. doi: 10.1590/S0102311X1999000500003

Arias, F. A.; Phélan, M. La medición del buen vivir rural: estudio de caso en el cantón Pucará, provincia de Azuay, Ecuador. Revista Venezolana de Análisis y Coyuntura, XXII(1), 2016.

Barroso, J. M. Prefacio. Una estrategia para un crecimiento inteligente, sostenible e integrador. In: Comisión Europea. Europa 2020. Bruselas, 2010. p. 2-3. Disponível em: <https://eurlex.europa.eu/LexUriServ/LexUriServ.do?uri=COM:2010:2020:FIN:ES:PDF>. Acesso em: 23 jun. 2019.

Bentham, J. An introduction to the principles of morals and legislation. Oxford: Claredon, 1996 [1789].

Bolívia. Asamblea Constituyente de Bolivia. Nueva Constitución Política del Estado. Congreso Nacional, Octubre 2008. Disponível em: <http://www.mindef.gob.bo/mindef/ sites/default/files/nueva_cpe_abi.pdf $>$. Acesso em: 23 jun. 2019.
Campaña, A. Em busca da definição de pautas atuais para o delineamento de estudos sobre condições de vida e saúde. Tradução de C. M. Bastos. In: Barata, R. B. (Org). Condições de vida e situação de saúde. Rio de Janeiro: Abrasco, 1997. p. 115-165.

Capra, F. A teia da vida. São Paulo: Cultrix, 2006.

Cerda, T.; Vera, X. Documento de trabajo: indicadores sociales y marcos conceptuales para la medición social. Santiago: Instituto Nacional de Estadísticas, 2008. Disponível em: <http://historico.ine.cl/canales/sala_prensa/ revistaseconomicas/documentostrabajo/30_06_09/documento_de_trabajo_indicadores_sociales.pdf $>$. Acesso em: 18 jun. 2019.

Coelho Junior, N. E.; Figueiredo, L. C. Figuras da intersubjetividade na constituição subjetiva. Interações, IX(17), p. 9-28, 2004.

Comisión de las Comunidades Europeas. Comunicación de la comisión al consejo y al parlamento europeo. Más allá del PIB: Evaluación del progreso en un mundo cambiante. Bruselas, 20 ago. 2009. Disponível em: <http:// eucyl.jcyl.es/web/jcyl/Eucyl/es/Plantilla100DetalleFeed/1277999678552/Publicacion/1251181086622/Redaccion>. Acesso em: 23 jun. 2019.

CEPAL - Comisión Económica para América Latina y el Caribe. Ecuador: Mapa de necesidades básicas insatisfechas. Comisión Económica para América Latina y el Caribe, División de Estadística y Proyecciones, 27 de julio de 1988. Disponível em: <https://repositorio.cepal.org/ bitstream/handle/11362/34763/S8800550_es.pdf?sequen$\mathrm{ce}=1 \&$ isAllowed $=\mathrm{y}>$. Acesso em: 23 jun. 2019 .

Comunicación de la comisión europea. Europa 2020: Una estrategia para un crecimiento inteligente, sostenible e integrador, Bruselas, COM (2010) 2020 final, de 3 de marzo de 2010. Disponível em: https://eur-lex.europa.eu/LexUriServ/ LexUriServ.do?uri=COM:2010:2020:FIN:ES:PDF. Acesso em 19 fev. 2020.

Daly, M.; Lewis, J. The concept of social care and the analysis of contemporary welfare states, British Journal of Sociology, 51(2), 281-298, 2000. doi: 10.1111/j. 1468-4446.2000.00281.x

Dolan P.; Peasgood, T.; White, M. Review of research on 
the influences on personal well-being and application to policy making. London: Defra, 2006.

Ecuador. Plan Nacional de Desarrollo 2017-2021: Toda una vida. Quito: Secretaría Nacional de Planificación y Desarrollo, 2017. Disponível em: <https://observatorioplanificacion.cepal.org/sites/default/files/plan/files/EcuandorPlanNacionalTodaUnaVida20172021.pdf>. Acesso em: 18 jun. 2019.

Ecuador. Asamblea Constituyente. Constitución del Ecuador. s.l. s.e. s.d. Disponível em: <https://www.finanzas. gob.ec/wp-content/uploads/downloads/2015/03/constitucion_de_bolsillo.pdf $>$. Acesso em: 23 jun. 2019.

Ecuador. Plan Nacional de Desarrollo / Plan nacional para el buen vivir 2009-2013. Quito: Secretaría Nacional de Planificación y Desarrollo, 2009. Disponível em: <http:// www.buenvivir.gob.ec/versiones-plan-nacional\#tabs2>. Acesso em: 1 jul. 2019.

Ecuador. Plan Nacional de Desarrollo / Plan nacional para el buen vivir 2013-2017. Quito: Secretaría Nacional de Planificación y Desarrollo, 2013. Disponível em: <http:// www.buenvivir.gob.ec/versiones-plan-nacional\#tabs $1>$. Acesso em: 1 jul. 2019.

Fernández, P. Psicología social, intersubjetividad y psicología colectiva. In: Montero, M. (Coord.). Construcción y crítica de la psicología social. Barcelona: Anthropos; Caracas: Universidad Central de Venezuela,1994. p. 49-107. (Serie Psicología social; 21).

Freire, P. Pedagogía de la indignación. Madrid: Morata, 2001.

Gudynas, E. Debates sobre el desarrollo y sus alternativas en América Latina. In: Grupo Permanente de Trabajo sobre Alternativas al Desarrollo. Más allá del desarrollo. Quito: El Conejo, 2011.p. 21-53. Disponível em: <http://rio20.net/ wp-content/uploads/2012/07/mas-alla-del-desarrollo_30. pdf $>$. Acesso em: set. 2018.

Gudynas, E. Desarrollo sostenible. Vivienda Popular, 18, p.12-19, 2009. Disponível em: <http://www.gudynas.com/ publicaciones/GudynasDesaSustVPopular09.pdf $>$. Acesso em: jun.2018.

Gudynas, E.; Acosta, A. El buen vivir o la disolución de la idea del progreso. In: Rojas, M. (Coord.). La medición del progreso y del bienestar. México: Foro Consultivo Científico y Tecnológico AC, 2011a. p. 103-110. Disponível em: <http://www.gudynas.com/publicaciones/capitulos/ GudynasAcostaDisolucionProgresoMx11r.pdf $>$. Acesso em: 13 jun. 2019.

Gudynas, E.; Acosta, A. La renovación de la crítica al desarrollo y el buen vivir como alternativa. Utopía y Praxis Latinoamericana, 16(53), 71-83, 2011b. Disponível em: $<$ http://www.gudynas.com/publicaciones/GudynasAcostaCriticaDesarrolloBVivirUtopia11.pdf $>$. Acesso em: 13 jun. 2019.

Hidalgo-Capitán, A. L. El buen vivir ecuatoriano en el contexto de la economía política del desarrollo. In: Anais do Primero Congreso internacional de estudios del desarrollo, Universidad de Cantabria, Santander, 2012a. Disponível em: <https://cooperacionecuador.files.wordpress. com/2014/03/el-buen-vivir-ecuatoriano-en-el-contexto-de-la-economc3ada-polc3adtica-del-desarrollo-antonio-luis-hidalgo-capitc3a1n-universidad-de-huelva.pdf $>$. Acesso em: 14 jun. 2019.

Hidalgo-Capitán, A. L. El buen vivir: la (re)creación del pensamiento del PYDLOS. Cuenca: PYDLOS, Universidad de Cuenca, 2012b.

Hidalgo-Capitán, A. L.; Cubillo-Guevara, A. P. Seis debates abiertos sobre el sumak kawsay. Íconos: Revista de Ciencias Sociales, 48, p. 25-40, 2014. Disponível em: <https:// revistas.flacsoandes.edu.ec/iconos/article/view/1204/1103 >. Acesso em: 23 jan. 2019.

Illich, I. La convivencialidad. In: Obras reunidas. México: Fondo de Cultura Económica, 1 v., 2006. p. 367-530.

Kahneman, D. Objective happiness. In: Kahneman, D.; Diener, E.; Schwarz, N. (Eds.). Well-being: The foundations of hedonic psychology. New York: Russell-Sage Foundation, 2003. p. 3-25.

León, M. Del discurso a la medición: propuesta metodológica para medir el buen vivir en Ecuador. Quito: Instituto Nacional de Estadística y Censos (INEC), 2015. Disponível em: <http://www.ecuadorencifras.gob.ec/wp-content/ uploads/downloads/2016/10/Buen-Vivir-en-el-Ecuador. pdf $>$. Acesso em: 18 jun. 2019. 
López-Ménendez, A. J. Reflexiones, retos y experiencias en la medición del bienestar y el Buen Vivir. In: Instituto Nacional de Estadísticas y Censos. Experiencias y metodologías internacionales de medición del bienestar. Quito: Instituto Nacional de Estadística y Censos, 2015. p. 197-216. Disponível em: <http://www.ecuadorencifras. gob.ec/documentos/web-inec/Bibliotecas/Libros/libro $\% 20$ buen\%20vivir-exp-met-inter.pdf>. Acesso em: 14 jun. 2019.

Quadros de Magalhães, J. L.; Ribeiro, T. El estado plurinacional como referencia teórica para la construcción de un estado de derecho internacional. In: Becerra Ramírez, M.; Martín, G. (Coords.). Estado de derecho internacional. México: Universidad Nacional Autónoma de México, 2012. p. 195-208.

Maggino, F. Methodologies to integrate subjective and objective information to build well-being indicators. In: Anais da International Conference from GDP to Well-Being: Economics on the road to sustainability. Ancona, December 3-5, 2009. Disponível em: <https://flore.unifi.it/retrieve/ handle/2158/370602/11439/maggino_-_paper.pdf $>$. Acesso em: 15 jun. 2019.

Mamani, F. H. Buen Vivir / Vivir Bien. Lima: Coordinadora Andina de Organizaciones Indígenas - CAOI, 2010.

Marlier, E.; Atkinson, A. B. Indicators of poverty and social exclusion in a global context. Journal of Policy Analysis and Management, 29(2), 285-304, 2010.

Max-Neef, M. A. Desenvolvimento à escala humana. Com contribuição de A. Elizalde e de M. Hopenhayn. Blumenau: Edifurb, 2012.

Mueller, C. C. O debate dos economistas sobre a sustentabilidade: uma avaliação sob a ótica da análise do processo produtivo de Georgescu-Roegen. Estudos Econômicos, 35(4), 687-713, 2005. doi: 10.590/S0101-41612005000400004

NEF - New Economic Foundation. The happy planet index 2.0. London: New Economic Foundation, 2009. Disponível em: <http://debis.deu.edu.tr/userweb//timucin.yalcinkaya/ Happy\%20Planet\%20Index\%20-\%202009.pdf>. Acesso em 23 jun. 2019.

Nussbaum, M. C. Creating capabilities: The human development approach. Cambridge: The Belknap Press of Harvard University Press, 2011.
Oxford Poverty \& Human Development Initiative. Para qué medir el bienestar subjetivo y psicológico? Humanum: Revista Latinoamericana de Desarrollo Humano, 80, 1-7, 2011. Disponível em: <https://www.ophi.org.uk/ wp-content/uploads/Bienestarsubjetivo.pdf $>$. Acesso em: 18 jun. 2019.

Pallaroso, F. A. A. Generación de un sistema de indicadores con el enfoque del buen vivir en el cantón Pucará, provincia del Azuay, Ecuador, al año 2012. Cuenca, Tese (Maestría en Desarrollo Local con Mención en Población y Territorio) - Universidad de Cuenca, 2014. Disponível em: <http:// dspace.ucuenca.edu.ec/bitstream/123456789/21026/1/tesis. pdf $>$. Acesso em: 23 jun. 2019.

Pena-Trapero, B. La medición del bienestar social: una revisión crítica. Estudios de Economía Aplicada, 27(2), 299-324, 2009. Disponível em: <http://www.revista-eea.net/ documentos/27206.pdf>. Acesso em: 18 jun. 2019.

Pérez Viramontes, G. Reconocimiento intersubjetivo de necesidades humanas para construir paz: el caso de Usmajac (Jalisco, México). Granada, Tese (Doctorado) - Universidad de Granada, 2010.

Phélan, M. C. Revisión de índices e indicadores de desarrollo: aportes para la medición del buen vivir (sumak kawsay). OBETS. Revista de Ciencias Sociales, 6(1), 6995, 2011.

Phélan, M. C.; Guillén, A. Aproximación metodológica para la medición subjetiva del buen vivir (Sumak Kawsay). In: Guillén, A.; Phélan, M. (Comp.). Construyendo el buen vivir: I Encuentro Internacional del Programa de Cooperación Universitaria e Investigación Científica. Cuenca: PYDLOS, 2012. p. 181-194.

PNUD - Programa das Nações Unidas para o Desenvolvimento. O que é desenvolvimento humano. [s.d.a]. Disponível em: <http://www.br.undp.org/content/brazil/pt/home/ idh0/conceitos/o-que-e-desenvolvimento-humano.html>. Acesso em: 24 jun. 2019.

PNUD - Programa das Nações Unidas para o Desenvolvimento. O que é o IDH. [s.d.b]. Disponível em: <http://www. br.undp.org/content/brazil/pt/home/idh0/conceitos/o-que-e-o-idh.html>. Acesso em: 25 jun. 2019.

Rojas, M. El bienestar subjetivo en México y su relación 
con indicadores objetivos. Consideraciones para la política pública. In: Garduno, L.; Salinas, B.; Rojas, M. (Coords.). Calidad de vida y bienestar subjetivo en México. México: Plaza y Valdés; Barcelona: Francesc Carbonell, 2005. p. 83-112.

Rosa, M.; Orey, D. C. O campo de pesquisa em etnomodelagem: as abordagens êmica, ética e dialética. Educação e Pesquisa., 38(4), 865-879, 2012.

Schavelzon, S. Plurinacionalidad y Vivir Bien/Buen Vivir: Dos conceptos leídos desde Bolívia y Ecuador post-constituyentes. Quito: Abya Yala; Buenos Aires: Clacso, 2015.

Sen, A. K. Desenvolvimento como liberdade. São Paulo: Companhia das Letras, 2000.
Stiglitz, J.; Sen, A.; Fitoussi, J.-P. Report by the Commission on the Measurement of Economic Performance and Social Progress. [2010]. Disponível em: <https://ec.europa.eu/ eurostat/documents/118025/118123/Fitoussi+Commission+report>. Acesso em: 5 jul. 2019.

Torres, G. A. Buen Vivir: dimensiones y retos desde la métrica. In: Instituto Nacional de Estadística y Censos (INEC). Experiencias y metodologías internacionales de medición del bienestar: una referencia para el Buen Vivir de Ecuador. Quito: Instituto Nacional de Estadística y Censos, 2015. p. 217-231. Disponível em: <http://www.ciberoamericana. com/pdf/BuenVivir.pdf>. Acesso em: 24 jun. 2019.

World Commission on Environment and Development. Report of the World Commission on Environment and Development: Our common future. Oslo, 1987. Disponível em: $<$ https://sustainabledevelopment.un.org/content/documents/5987our-common-future.pdf $>$. Acesso em: 3 jul. 2019. 